\title{
Students' competencies discovery and assessment using learning analytics and semantic web
}

\author{
Khaled Halimi \\ 8 Mai 1945 Guelma University, Algeria \\ Hassina Seridi-Bouchelaghem \\ Badji Mokhtar Annaba University, Algeria
}

Traditional content-based assessment systems, which depend on the score as a key criterion for students' evaluation, have proven to have many drawbacks, especially with the development of learning methods in recent years. Based on these developments, there is a need to adopt new assessment methods to assess the actual skills of students in the digital age. Therefore, the competency-based assessment approach is adopted in this paper to address the subject of students' competency modelling and discovery in technologyenhanced learning systems. This method of assessment is perfectly suited to modern teaching trends. The authors proposed an approach of assessment semantic analytics to be used for discovering and assessing students' competencies. This study notes that, all knowledge about students and their competencies has been modelled by semantic representations. Student's models have been subjected to a set of learning analytics approaches to analyse data generated by students' activities in order to discover their explicit and latent competencies hidden behind their activities. This experimental study indicates that the competency-based assessment approach is efficient and expected to show significant advantages in evaluating students' competencies.

Implications for practice or policy:

- Students become able to organise their gains, then integrate and employ them in solving life's problems.

- Educators get to know more about the extent to which the objectives of their educational process are achieved by evaluating the intellectual, cultural, knowledge, and skilful assets that the learners obtain.

- Educational policymakers can have a pedagogical and technical vision to move from the culture of content-based evaluations to a competency-based assessment.

Keywords: competency-based assessment, semantic web, technology enhanced learning, personalisation and profiling, artificial intelligence, qualitative survey

\section{Introduction}

Assessment is one of the most crucial phases in the learning process. The success of the education process is strongly linked to evaluation. Assessment helps students to recognise their learning outcome, to get an idea about their progress, and to adjust the pace of their learning by assuming greater responsibility and initiatives (Ellis, 2013). Most learning environments adopt an assessment approach based on the learning score or outcomes. This way of evaluation could be one of the factors that lead to students' failure due to the high stress of thinking about assessment and exam scores (Kamalova et al., 2021). In addition, most of the students are unable to apply what they have learned because they learn a piece of knowledge, but they can't apply it in complex contexts. This issue prompted us to delve into the competency-based assessment (CBA) approach.

The CBA is a modern pedagogical method that aims to bring out the learners' competencies and prepare them to face the challenges they encounter daily. It does not try to restrain the classical pedagogy, but it does emphasise goals that take into account learning enhancement. It encourages moving from a contentbased evaluation paradigm towards a competency-based assessment. We note that this is not an easy task since the assessment of students' competencies is a complex and challenging process. It is a shift that involves significant changes in the design of online evaluation systems, not only from a pedagogical point of view, but also by incorporating sophisticated computing technologies. 
To this effect, the scope of this paper is to introduce a new approach of students' assessment. It presents a semantic assessment analytics that addresses how learning analytics combined with the use of semantic web techniques can be used in the modelling and assessment of students' competencies. Therefore, all knowledge is modelled through a semantic web representation, then a deep analysis of students' activities is performed using learning analytics approaches, namely: text classification, sentiment analysis, topic extraction and hashtag suggestion, grammar correction, and text comparison. The assessment module, which relies on the results of the analytics approaches combined with the use of inferring and reasoning mechanisms of semantic web allows us to discover latent and implicit competencies that help to better assess student's knowledge.

The suggested approach is applicable to college students pursuing an online computing course. Moreover, this research applies this method to answer the following questions:

- How can students' competencies be assessed?

- How can their competencies be discovered?

- How can students' activities be translated into acquired competencies?

- Is there any typical pedagogical model that supports the assessment of students' competencies?

To this end, we introduce a brief overview of related concepts of competency assessment, semantic web, and learning analytics. Then, we present the semantic assessment analytics model, highlighting the suggested ontology and schema, the discovery of students' competencies model, the pedagogical competency-based model, and the different learning analytics techniques applied in this approach. Finally, we present the evaluation of this approach through experimentation.

\section{Literature review}

Researchers are always looking for new ways to improve students' learning outcomes (Rafiola et al., 2020). They constantly attempt to reform the education process, because assessment is one of the essential components of the reformation process or operation. Assessment can be considered as a mirror of the learning process. It helps to enhance the curricula, for example, to monitor the effectiveness of education and to provide a complete perception of the students' mastery of the acquired knowledge. Assessment helps teachers develop their learning content and allows them to know what students understand and how well they respond to the teachers' educational goals.

There are many definitions of the learning assessment. As described by Adeshola and Abubakar (2020, p. 153), assessment is "the core backbone of the learning process, and the central goal of assessment is to support and enhance learning". Ambarwati and Damayanti $(2021$, p. 4) defined assessment as "the process of collecting and processing information to measure the achievement of learners' learning outcomes." Based on the above definitions, we define assessment as a process that aims to make a precise and objective judgment on the students' inputs and outputs, and to measure their learning outcomes in terms of assimilated knowledge, advanced understanding, and acquired skills. It also tries to identify their weaknesses and strengths to make appropriate decisions for learning reformation.

The score is the cornerstone of most assessment methods used in today's learning systems. This way of evaluation could be one of the reasons why students fail (Koretz, 2002). First, the score is changeable from one system to another. Moreover, although many consider the score as a culmination of the learning process and an engine of healthy competition, many students claim that their score does not reflect their real educational levels. Similarly, many researchers agree that the score would also be too often the trigger of anxiety for students (Ahmed et al., 2009). The question we should ask now is how to reduce the impact of the evaluation frustration based on the score and make it more constructive and more representative of the students' level of knowledge or understanding? Looking for an answer to this question drives us to move towards the use of the CBA. In the following section, emphasis will be given to the different concepts and aspects that characterise this approach. 


\section{Competency-based assessment (CBA)}

CBA aims to develop and control competencies of learners when facing challenges in different situations (Idrissi et al., 2020). It does not contradict the classical pedagogy, but it strengthens the evaluation process. Assessment through this approach requires not only the recall of knowledge but also the use and reuse of that knowledge in complex situations. Lasnier (2000, p. 315) described competency as "know-how that incorporates skills and knowledge, which is complex, refers to cognitive, affective, social or psychomotor skills and is specific to a set of situations (contexts)". As described by Paquette (2002, p. 187), competency is "a relationship between an actor, skill, and knowledge". According to Coulet $(2011$, p. 17) a competence is "a dynamic organisation of activity, mobilised and regulated by a subject to face a given task in a given situation".

With CBA, there is no score in terms of numbers, but an evaluation of competencies. For instance, for a homework assignment, the points are forgotten, and specific competencies are chosen to be evaluated and determined in advance by the pedagogical team. A decision is taken for each assessed competency to check whether it is acquired, to be acquired, or not acquired. This type of assessment is explicitly designed to enable students to identify their strengths and weaknesses. We strongly believe that CBA will substantially impact students' cognitive achievement, based on the Pygmalion effect theory, which describes the phenomenon whereby others' expectations of a target person affect the target person's performance (Feldman \& Prohaska, 1979).

Students' competencies assessment is a complex process (Zlatkin-Troitschanskaia \& Pant, 2016). There are real reasons that make it a challenging issue. Through our research in this field, we summarised the challenges as: modelling and representing competencies, the discovery of latent competencies, assessment of competencies, and the pedagogical model that fits with the competency-based assessment.

\section{Semantic learning analytics for modelling and discovering competencies}

To address the challenges mentioned above, we believe that incorporating computational techniques, for example, semantic web and learning analytics, data mining, and data visualisation, can play a crucial role in supporting and enhancing the CBA. This method has been called embedded assessment, and it has not yet been fully developed (Haugen \& Metcalf, 2019). In this paper, the focus is on how to use the semantic web and learning analytics to assess students' competencies.

According to Abecker and Decker (1999), competence is a way to put knowledge into practice in a specific Knowledge in learning is the collection of expertise, experience, and information that students use during the execution of their tasks context.. In the context of competence management, competencies are regarded as a kind of knowledge, so that they could be modelled and retrieved like any other knowledge.

Semantic web can be used to model competencies since it enables machines to perform tasks more effectively and efficiently, in large, distributed, problem-based, multi-actor, multi-resource learning spaces. In a semantic web structure, data is defined and linked so that it can be used by machines not only for display purposes but for automation, integration, and reuse between and across different applications (Okoye et al., 2020). The main idea of semantic web (machine-readable content, common sense, shared vocabulary) is therefore appropriate to meet the requirement of competencies assessment. This is supported by the evaluation process which leverages the meaning expressed by semantics. Semantics are presented in relationships between concepts of the ontology and by the discovery of new competencies (knowledge) by means of inferring and reasoning mechanisms of the semantic web (Mayfield \& Finin, 2003). Ontologies offer rich semantics for annotating and representing competencies, and subsequently, can help improve accuracy in assessment by avoiding ambiguities through the use of terminology.

One of the main challenges faced by teachers in technologically enhanced learning environments is capturing, tracking, and analysing massive data generated during the learning activities (Johnson et al., 2008). To support teachers in this complex task, it is essential to rely on computational techniques (e.g., artificial intelligence and data mining) to check, sort, and analyse students' activities to better evaluate their 
competencies (Romero \& Ventura, 2020). Having noted these challenges, learning analytics approaches could greatly support competency assessment (Ally, 2019).

The term learning analytics, commonly refers to computer, mathematical, and statistical techniques used to extract relevant information from huge sets of data. Siemens (2013, p. 1381) defines learning analytics as "the use of intelligent data, learner-produced data, and analytical models to discover information and social connections, and to predict and advise on learning". The objective of this domain is to analyse all data produced by students, with the aim of personalisation and adaptation of learning through a predictive dimension. In general, analytics is used to give meaning to the students' activity. As described by Larrabee Sønderlund et al. (2019), learning analytics is an emerging field in which sophisticated data analysis tools are used to improve learning and education. Nkhoma et al. (2020, p. 809) affirmed that "learning analytics methods have been exploring the potentials of unstructured data, such as written texts and assignments, to improve teaching and learning."

A recently emerged research field is assessment analytics. It consists of the processing and analysis of massive assessment data generated by students' activities using learning analytics techniques (Bayrak, 2021). Assessment analytics aims to extract new learning indicators to be interpreted, and undoubtedly contribute to the improvement of the assessment process. Cooper (2015) proposed an assessment analytics definition based on the learning analytics definition of Siemens (2013) with a little modification. According to Cooper (2015, p. 15), "it is the measurement, collection, analysis, and reporting of data about learners and their contexts, for purposes of understanding and optimising learning and the environments". Along these lines, this study adopts the definition of Cooper by adding a semantic layer to represent students' competencies, and allowing for inference of new knowledge to discover latent competencies that may be hidden behind students' activities. Typically, we define it as the modelling, measurement, collection, analysis, and reporting of students' data using semantic web representations and learning analytics approaches, for purposes of enhancing the assessment process and for the discovery of latent competencies. This paper addresses this emerging research area and proposes a semantic assessment analytics model to enhance competency-based assessment.

\section{Related works in semantic web technologies and learning analytics}

Namahoot et al. (2020) described the design, development, and testing of a computerised adaptive testing system for English language based on a testing process using an ontology of English language. Khdour (2020) proposed a semantic-based framework that automates the process of electronically assessing the answers of questions on e-learning systems based on their semantic descriptions. Rezgui and Mhiri (2020) presented a framework specification for lifelong competency management and development (LCMDF). The framework provides a unifying semantic foundation in the form of a set of controlled vocabularies for describing competencies and their related details within the contexts of technology-enhanced competencybased learning and training. Choi and Cho (2020) introduced a framework of a learning analytic method including assessment design, data mining method using social network analysis, and analytic method using a Bayesian network to analyse the learners' performances based on a computational psychometric framework. The scalable competence assessment through a learning analytics approach (SCALA) project, is an analytics system that tracks how the user interacts with resources and how students and teachers interact among themselves to support competency assessment (Rayón et al., 2014). Romero et al. (2012) proposed an ontology called an ontology network (AONet), which conceptualises the e-assessment domain, enriched with rules to take into account the pedagogical and the technical aspects of the assessment.

Through the analysis of related works, the authors found that there are no research works that combine semantic web and learning analytics approaches to support the competency-based assessment. Therefore, our contribution is articulated around the modelling and discovery of students' competencies using semantic web and learning analytics technologies. An analysis of the students' activities was performed. This consisted of text classification, sentiment analysis, topics extraction, and text clustering. This was done with the support of the intelligent inferring mechanism of semantics to discover and assess latent competencies hidden behind student activities. A detailed description of the proposed approach is presented in the next section. 


\section{Model of the competency-based semantic analytics assessment}

To explain the proposed approach, the SoLearn system (Social-based Learning Environment) was used. SoLearn was developed by Halimi et al. (2014), and addresses the development of online learning systems based on semantic and social web technologies. In this work, we have added the learning analytics technologies to support the students' competencies assessment. As a social learning tool, SoLearn establishes an online meeting space between teachers and learners. It enables the creation of groups learners with different interests, levels of knowledge and personalisation, for resource sharing, communication, asking questions, sharing posts, and receiving notifications, feedback, and recommendations.

\section{The conceptual model}

In this section, the system's conceptual model and all of its main components are presented in detail. As illustrated in Figure 1, all knowledge is modelled by using semantic web technology and schema. Next, a deep analysis of learner behaviour and learning content is performed using the learning analytics modules to analyse the data generated by students' activities and evaluates them according to the competency approach, as well as to discover new latent competencies.

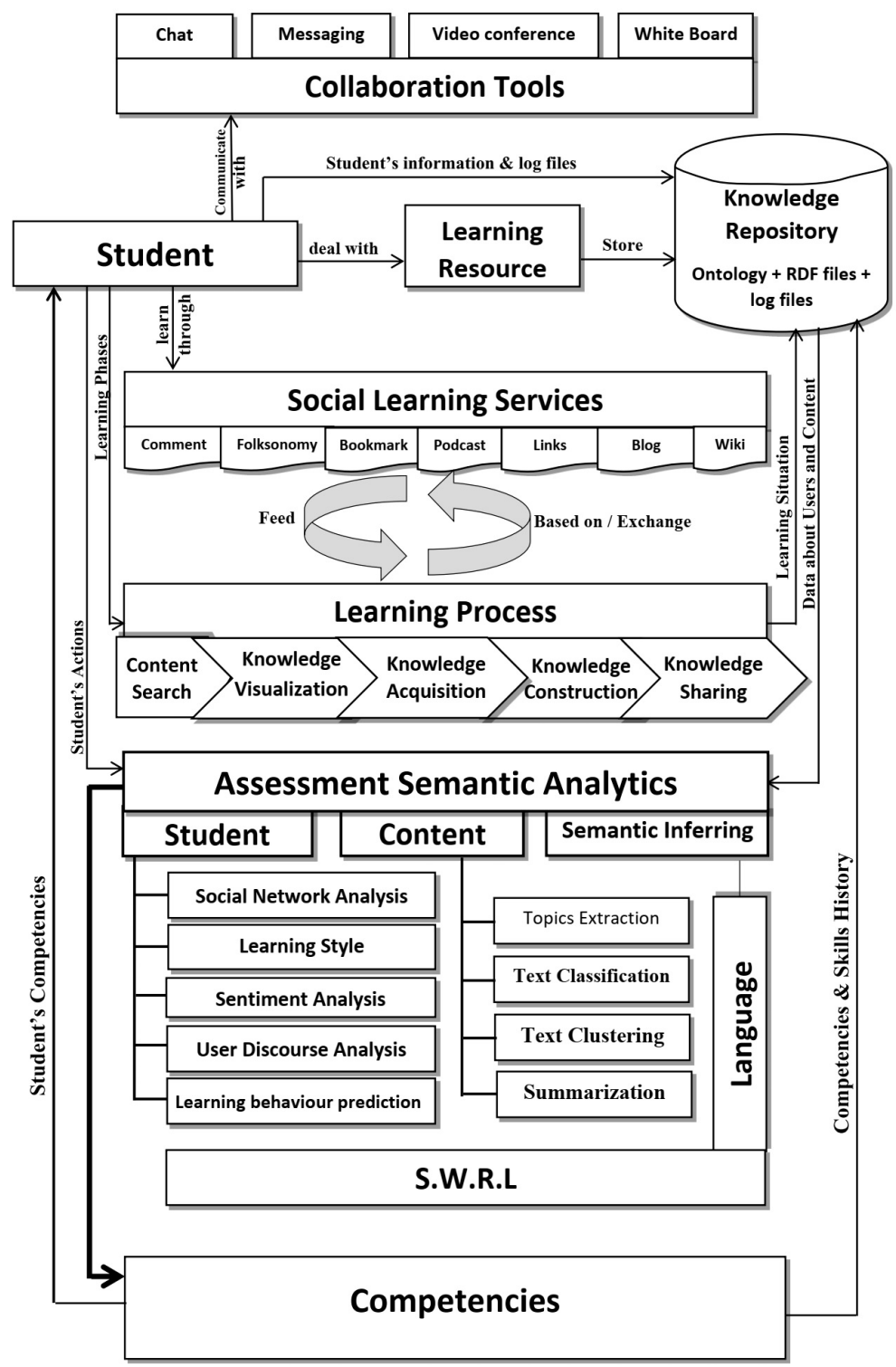

Figure 1. The system conceptual model 


\section{Knowledge representation (semantic modelling)}

Using the semantic web technology and schema allows us to semantically annotate all resources presented in the system. This improves accuracy in evaluating the students' competencies. It also avoids ambiguities in terms of terminology and allows for intelligent inference or reasoning. The domain of computing has been chosen, and a previously developed ontology by Halimi et al. (2014) has been employed - updated in this work to support the assessment of students' competencies, as shown in Figure 2. In the context of our work, the ontology allows us to formally define different users, competencies, evaluation modalities, assessment tools, learning resources, learning styles, and learning strategies. A set of properties is also presented, for example, properties that relate semantically different objects. For instance, hasCompetency is the property that links a student with a competency. It is important to mention that we formulated it with the RDF triplet, for example, <student, hasCompetency, Competency>. Figure 2 shows the proposed ontology in which we have modelled competencies and their related information in the Competency class. As presented in Figure 3, we also defined sets of subclasses, namely: approach, argumentation, linking, processing. These subclasses, in turn, have further subclasses; for instance, we can find that the competency Approach has the subclasses: adaptation, planning, and reporting.

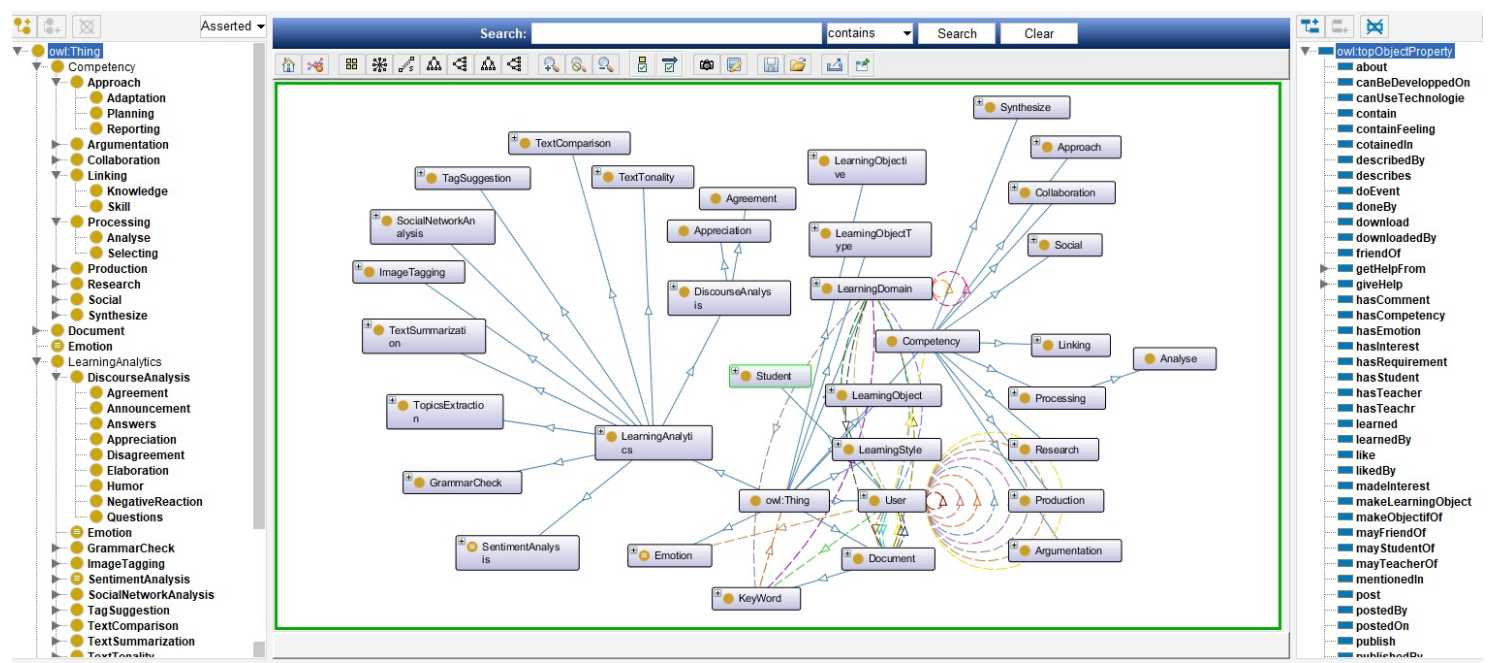

Figure 2. Extract of the ontology with Protégé Editor 2000

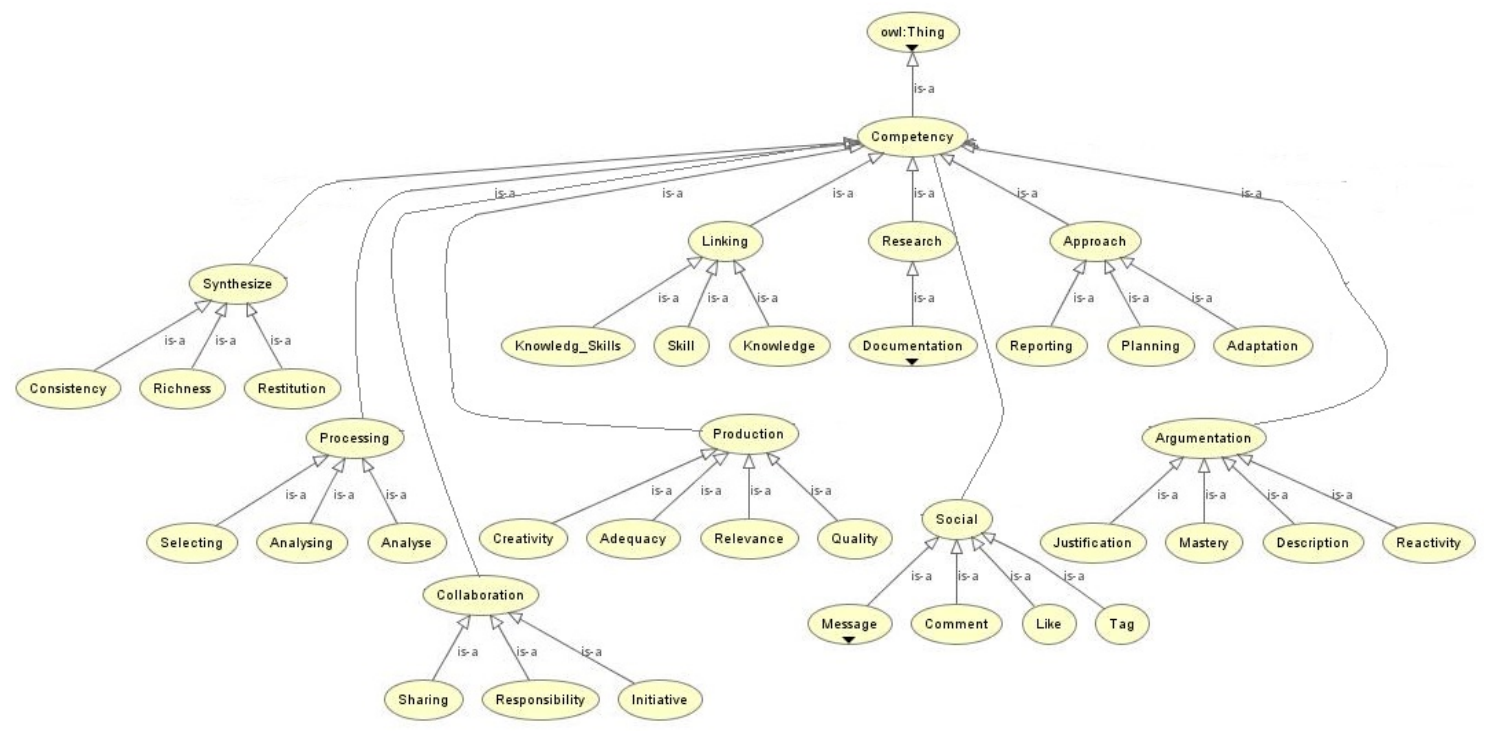

Figure 3. OntoGraph of the competency class

It is noteworthy to mention that we have also modelled the different learning analytics approaches used in the system in the LearningAnalytics class. As presented in Figure 4, we defined a set of sub-classes, namely: 
discourse analysis, topics extraction, sentiment analysis. These subclasses, in turn, have subclasses. For instance, the class Discourse Analysis has subclasses: agreement, question, elaboration.

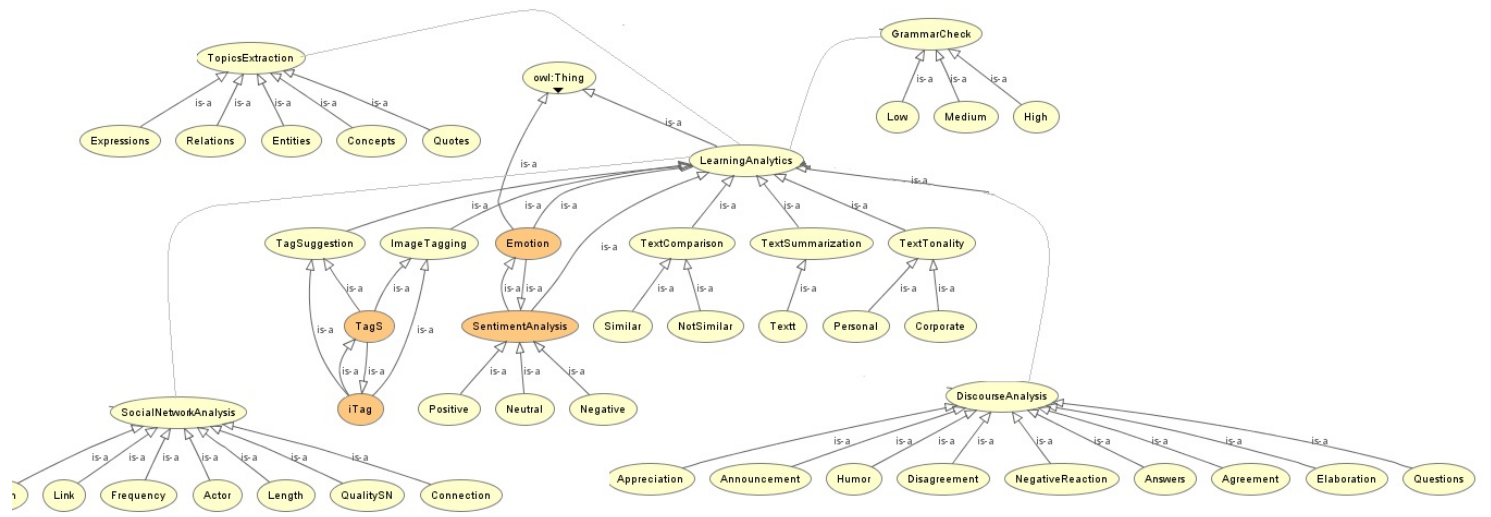

Figure 4. Ontograph of the learning analytics class

The students' model

In order to enhance the CBA process, the system should understand the students' activities and behaviours. Therefore, to increase this understanding, students' activities have been modelled with a semantic representation. The purpose of the students' modelling is to give a complete description of all the aspects related to their activities. It is necessary that the model must have all knowledge about a student (cognitive level, competencies, skills, goals, preferences, learning styles, history). This knowledge is built either through the explicit acquisition of interactions with the system or by the implicit use of semantic inference rules. The students' model is defined as an RDF file comprising all knowledge about the students. This serves as a portfolio that can be used by other external systems to ensure openness and consistency. We proposed describing the student with well-defined statements (axioms), as shown in Figure 5. A statement is defined as an abstract notion in the ontology, which presents the combination of a resource, property, and value. For instance, we can model a student with knowledge about their personal information: first name, family name, e-mail address. These concepts are related to their values with a set of semantic relations, hasFamilyName, hasFirstName, hasEmail, and described semantically using the predicate, $<$ Student, hasFamilyName, 'Family Name'>, as well as knowledge about the students' competencies, <Student, acquired_Competency, 'Creativity'>.

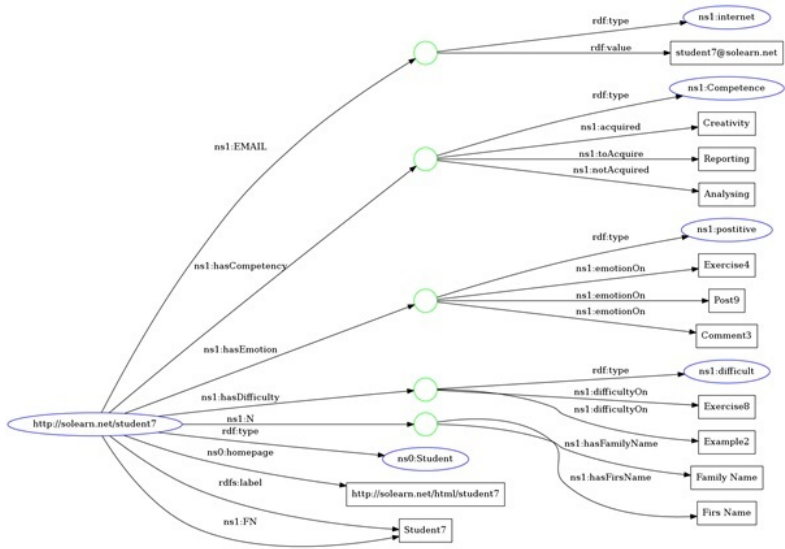

Figure 5. Student model described in RDF format

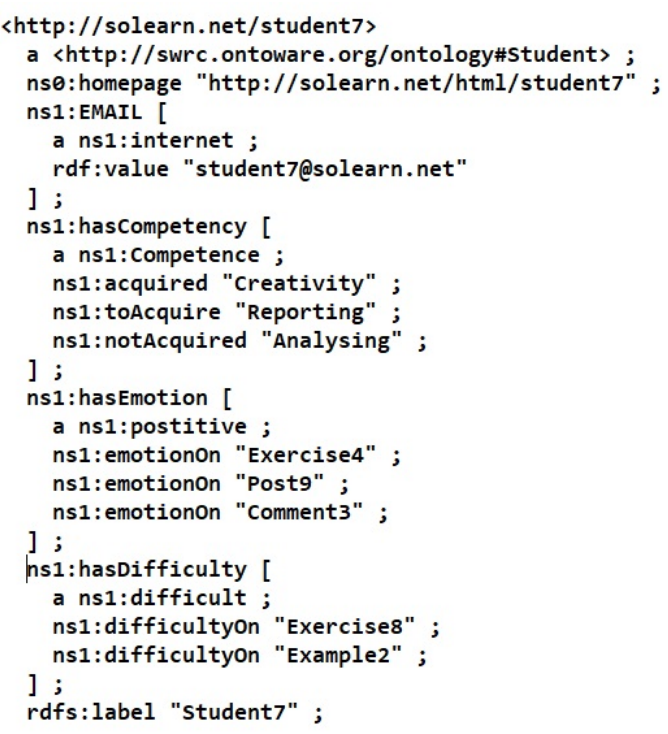




\section{A competency-based assessment grid}

In this section, a competency assessment grid for a computer-based content is presented. It was created based on the definition of the competency classes we presented in the ontology. To realise this grid, we worked on three main phases. The first phase consists of identifying the learning objectives and evaluation criteria, through a study of the evaluation (constructs) grids published in the literature, for example the work presented in Patterson et al. (2013), and through a collection of evaluation tools used by teachers in different levels. The second phase concerns the development of evaluation criteria to specify the expected competencies of students. The third phase involves the testing and final revision, which allowed us to highlight a certain number of flaws, particularly around the overlapping of certain sub-criteria and redundancies. These were consequently corrected. Table 1 shows the students' activities and behaviours carried out in the system, making it possible to detect such a competency. The grid is composed of criteria, and each criterion is divided into several levels.

Table 1

The competency-based assessment grid

\begin{tabular}{|c|c|c|}
\hline Competency & & Behaviour of the student versus competency \\
\hline \multirow[t]{3}{*}{ Approach } & Adaptation & $\begin{array}{l}\text { Does the content added by the learner adapted to the chosen } \\
\text { subject? }\end{array}$ \\
\hline & Planning & $\begin{array}{l}\text { Does the learner have the ability to set specific objectives and to } \\
\text { set deadlines? }\end{array}$ \\
\hline & Reporting & Write reports about what was done and what was not done. \\
\hline \multirow[t]{4}{*}{ Argumentation } & Description & $\begin{array}{l}\text { Description of the general problem, tools used to solve the } \\
\text { problem. }\end{array}$ \\
\hline & Justification & Use of varied and relevant supports for argumentation. \\
\hline & Mastery & The knowledge provided by the student is well mastered? \\
\hline & Reactivity & $\begin{array}{l}\text { Answers to the questions show a good knowledge of the treated } \\
\text { part of the subject as well as a knowledge of the whole subject. }\end{array}$ \\
\hline \multirow[t]{2}{*}{ Collaboration } & $\begin{array}{l}\text { Initiative and } \\
\text { responsibility }\end{array}$ & $\begin{array}{l}\text { Does the work contain investigation, experience, with different } \\
\text { forms, for example video? }\end{array}$ \\
\hline & Sharing & $\begin{array}{l}\text { Have the requests for interventions been sent to internal or external } \\
\text { contacts? }\end{array}$ \\
\hline Linking & Linking & $\begin{array}{l}\text { Does the learner have the ability to relate theoretical knowledge to } \\
\text { practical problems? Or vice versa? }\end{array}$ \\
\hline \multirow[t]{2}{*}{ Processing } & Analysing & $\begin{array}{l}\text { Does the learner have the ability to make a comparison, critical } \\
\text { analysis, demonstration, or classification of selected information? }\end{array}$ \\
\hline & Selecting & $\begin{array}{l}\text { Does the learner have the ability to extract a part of the information } \\
\text { from a resource? }\end{array}$ \\
\hline \multirow[t]{4}{*}{ Production } & Adequacy & $\begin{array}{l}\text { The content of the production is it in perfect adequacy with the } \\
\text { subject? }\end{array}$ \\
\hline & Creativity & $\begin{array}{l}\text { Originality: Does the learner make a contribution in the same } \\
\text { context but in a different format than what was requested? }\end{array}$ \\
\hline & Quality & $\begin{array}{l}\text { Quality of: phrases, photos, drawings, and diagrams are carefully } \\
\text { chosen. }\end{array}$ \\
\hline & Relevance & $\begin{array}{l}\text { Scientific validity: reliability of documentary sources, scientific } \\
\text { accuracy of the subject, or validity of experiments. }\end{array}$ \\
\hline \multirow[t]{2}{*}{ Research } & Methods & Does the learner correctly use information retrieval methods? \\
\hline & Storage & Is the information appropriately stored in the storage space? \\
\hline Social & $\begin{array}{l}\text { Comment, like } \\
\text { message. }\end{array}$ & $\begin{array}{l}\text { Does the learner use "Comments" to ask, answer, or criticise? } \\
\text { Does the learner use the "Like" option to express their sentiments } \\
\text { towards a subject? Does the learner use "Messages" to } \\
\text { communicate with their peers? }\end{array}$ \\
\hline
\end{tabular}

$\begin{array}{ll}\text { Synthesise } \quad \text { Consistency } & \begin{array}{l}\text { The content is organised into several distinct parts: introduction, } \\ \text { personal work, examples, openness to other issues. }\end{array}\end{array}$


Restitution The synthesis mentions a criticism (positive and negative points): with regard to oneself, the group, others.

Richness The synthesis uses a clear expression, and the vocabulary is rich.

\section{A competency-based pedagogical model}

To help students discover their apparent and hidden competencies, educators must overcome the traditional learning strategies that depend on the transfer of blocks of knowledge from teacher to students. Teachers should evaluate the students' knowledge not only through retrieval tests, but with a strategy taking into account that students live in a social experience to develop ideas, evolving in their learning, and discovering their real competencies, since students nowadays are social-based learning-oriented. For this reason, we updated the model of the social learning process presented in (Halimi \& Seridi-Bouchelaghem, 2019), which was based on the connectivism learning theory. Connectivism learning theory describes how learning occurs and develops across social learning networks. As shown in our model depicted in Figure 1, on the one hand, social learning services feed the learning process with necessary knowledge created and shared by expert users (teachers or experienced students). On the other hand, it is the learning process that stimulates students to use social learning services, allowing them to trigger their competencies. The folksonomy module, for instance, can push students to find content or users in relation to a specific learning domain. This module can develop the competency of research, analysing, or selecting. The knowledge creation module drives learners to create or share learning objects through wikis or blogs. It develops the learners' competence of production, argumentation, linking, and creativity. The semantic content search module provides the big picture of the learning objective and develops the competency of description, adaptation, and planning with previous or subsequent objectives. This module extracts all knowledge stored in an ontology as concepts and relationships between them (a taxonomy) so that students will be able to find where and how they will begin learning. The knowledge visualisation module allows students who do not have any knowledge about a specific topic to rapidly get its general meaning and relate new and old information, this develops and improves the students' linking competency. The knowledge acquisition module allows students to obtain appropriate learning resources, or to receive answers and feedback in the form of comments or messages from the more knowledgeable others, at any time. This develops and improves the students' competency of collaboration, reporting, taking initiative, and responsibility.

We also updated the learning objects model, to enable the system to know which competence has been acquired, which one is being acquired, and which one is not acquired. The model was based on dividing learning resources into a set of learning units. Each unit was divided into a set of modules, and each module was also divided into a set of courses. Each course now contains a set of learning entities (definition, summary, illustration, example). Each entity can have different formats (for instance, definition is a text file, while illustration is a video). We also defined semantic relationships between these entities, for example, <definition, isPrerequisiteOf, illustration>. This updated design takes into account the students' differences, where a single course structure cannot be appropriate for all students. This decomposed approach is advantageous in the sense that it allows for quick retrieval of knowledge and does not force students to consume content that does not fit with their preferences. It enables effective assessment of the students' competencies, because it is unfair to subject students to an evaluation of the whole lesson and to judge them to have failed, despite, them having succeeded in acquiring knowledge and skills in some parts of the course. For instance, they were unable to solve an exercise, but they were able to give a good example about the problem. All knowledge about content and students' actions generated in all previous phases are stored in the knowledge base as RDF files to be used in the different learning analytics modules.

\section{Learning analytics towards service of competencies assessment}

This study proposes that the semantic analysis of students' activities supports the assessment of their competencies. Tracking students' activities using semantic models gives the analytics process the advantage of exploiting the meaning expressed by semantics (relationships between concepts) defined in the ontology, and enabling further inferences on the captured datasets. In Table 2, we present how the different learning analytics approaches provide the system with the means to detect students' competencies. 
Table 2

The learning analytics approaches

\begin{tabular}{|c|c|}
\hline Technique/tool & Intended/targeted competency \\
\hline $\begin{array}{l}\text { Social network analysis } \\
\text { Identify interactions which promote the } \\
\text { learning process. }\end{array}$ & $\begin{array}{l}\text { Social } \\
\text { - Does the student have social competency? } \\
\text { - Messaging, tagging, commenting, adding friends. }\end{array}$ \\
\hline $\begin{array}{l}\text { Sentiment analysis } \\
\text { Extract the emotional state of students } \\
\text { towards learning resources. }\end{array}$ & $\begin{array}{l}\text { Emotional } \\
\text { - Students' productions or learning outcomes have a } \\
\text { positive, negative, or neutral emotion. }\end{array}$ \\
\hline $\begin{array}{l}\text { Discourse analysis } \\
\text { Classify students' texts into questions, } \\
\text { answers or, more fine-grained categories } \\
\text { such as agreement, disagreement. }\end{array}$ & $\begin{array}{l}\text { Argumentation, processing, reactivity } \\
\text { - Students understand new terminology after it has been } \\
\text { used in the course; } \\
\text { - Students give critiques, judgments, or ask questions. }\end{array}$ \\
\hline $\begin{array}{l}\text { Topics extraction } \\
\text { Extracts relevant information such as } \\
\text { Named Entities, concepts as well as facts } \\
\text { (dates, time expressions, quantities) from } \\
\text { bodies of text. }\end{array}$ & $\begin{array}{l}\text { Production, linking, richness } \\
\text { - Understand the main content of student's resources } \\
\text { - Determine relations with other objects; } \\
\text { - Determine the knowledge type of content: know } \\
\text { what, know why, or know how. }\end{array}$ \\
\hline Hashtag suggestion & Adequacy, creativity, quality, relevance \\
\hline $\begin{array}{l}\text { Returns list of tag suggestions According to } \\
\text { semantic relevancy and tag popularity. }\end{array}$ & $\begin{array}{l}\text { - The content of the production is in perfect adequacy } \\
\text { with the subject. }\end{array}$ \\
\hline Text tonality & Reporting, description, justification \\
\hline $\begin{array}{l}\text { Determines the tonality of a text - corporate } \\
\text { (formal) or personal (informal). }\end{array}$ & $\begin{array}{l}\text { - Helps distinguish between students' personal } \\
\text { productions and other texts. }\end{array}$ \\
\hline Grammar check & Quality, mastery \\
\hline Determines the ling & $\begin{array}{l}\text { Detects the most subtle errors in a text, corrects } \\
\text { grammar and spelling mistakes, identify stylistic } \\
\text { repetitions, run-on sentences, redundancies, and more. }\end{array}$ \\
\hline Text comparison & Quality, responsibility, mastery \\
\hline $\begin{array}{l}\text { Allows to make a text comparison and find } \\
\text { the differences between two texts. }\end{array}$ & $\begin{array}{l}\text { - Comparing students' productions with what the } \\
\text { teacher has asked to check their mastery and quality } \\
\text { of productions. }\end{array}$ \\
\hline Image tagging & Creativity, mastery, linking, relevance \\
\hline $\begin{array}{l}\text { Enables automatic adding of a label to an } \\
\text { image }\end{array}$ & $\begin{array}{l}\text { - Check whether the label of the student's image is } \\
\text { matching the problem. } \\
\text { - Shows a sense of creativity, the fact that the learner } \\
\text { has responded with another type of media. }\end{array}$ \\
\hline Inferring and reasoning & Description, relevance, richness \\
\hline $\begin{array}{l}\text { Enrich learner's profile with new } \\
\text { knowledge inferred by semantic rules. }\end{array}$ & $\begin{array}{l}\text { Discover new facts about students in order to enrich } \\
\text { the relevance of their productions. } \\
\text { - Discovery of latent competencies. }\end{array}$ \\
\hline Document structure analysis & Consistency, selecting, quality \\
\hline $\begin{array}{l}\text { Grouping a set of texts in such a way that } \\
\text { texts in the same cluster are more similar to } \\
\text { each other. }\end{array}$ & $\begin{array}{l}\text { - Check if the students' content is organised into } \\
\text { several distinct parts: introduction, personal work, } \\
\text { examples, reports to other issues. }\end{array}$ \\
\hline
\end{tabular}

The analytics process is based on the analysis of the students' RDF files, which contain all the actions and activities carried out during their learning process and evaluation. Thanks to the inferring and reasoning mechanisms supported by the semantic web schema; new knowledge about students' activities is extracted from the ontographs. This provides the opportunity to discover unexpected elements that can be used to improve the assessment process.

By using the Discourse Analysis module of the uClassify API (a free machine learning web service enabled using text classifiers), the system extracts concepts that are contained in any text (e.g., comments, posts) produced by the students. It can distinguish questions from answers, for example, whether the answer is an 
agreement or disagreement, whether there is humour in the text. We performed this analysis to discover what students knew, understood, or misunderstood. This module provides some conclusions: You give many critics, You give more judgments, You ask a lot of questions. Consequently, the results of this analysis enable the system to decide if a student has mastery, the argumentation, or analysis competencies.

As for the use of the Document Structure Analysis module, the system can establish a clear and understandable structure of the students' production, through the content they produce and share. The system extracts concepts from any shared text, then it projects the extracted concepts to the ontology, though using semantic relations, inference rules, and SPARQL queries. The system determines the learning resources' domain, determines the learning objective of any object (e.g., analysis, synthesis), determines relations with other objects, and determines different competencies as illustrated in Figure 6.

As an example, a teacher asks students to upload pedagogical entities about Java. The system classifies the students' pedagogical entities and subjects them to the ontology to extract all the knowledge in relation to them. Suppose that the system detects that the summary7 of student4 talks about Java Applet, which has a required semantic relation with the object "Java" as defined in the ontology: <lo:JavaApplet lo:hasRequirement lo:JAVA>. Then, there is a semantic relation whereby the system concludes that student 4 has the competency of linking. Now suppose that student11 added example9 that talks about JavaScript. The latter is described in the ontology as:<lo:JavaScript lo:isDifferentFrom lo:JAVA $>$. Henceforth, the system concludes that student11 has not acquired the linking competency in this case.

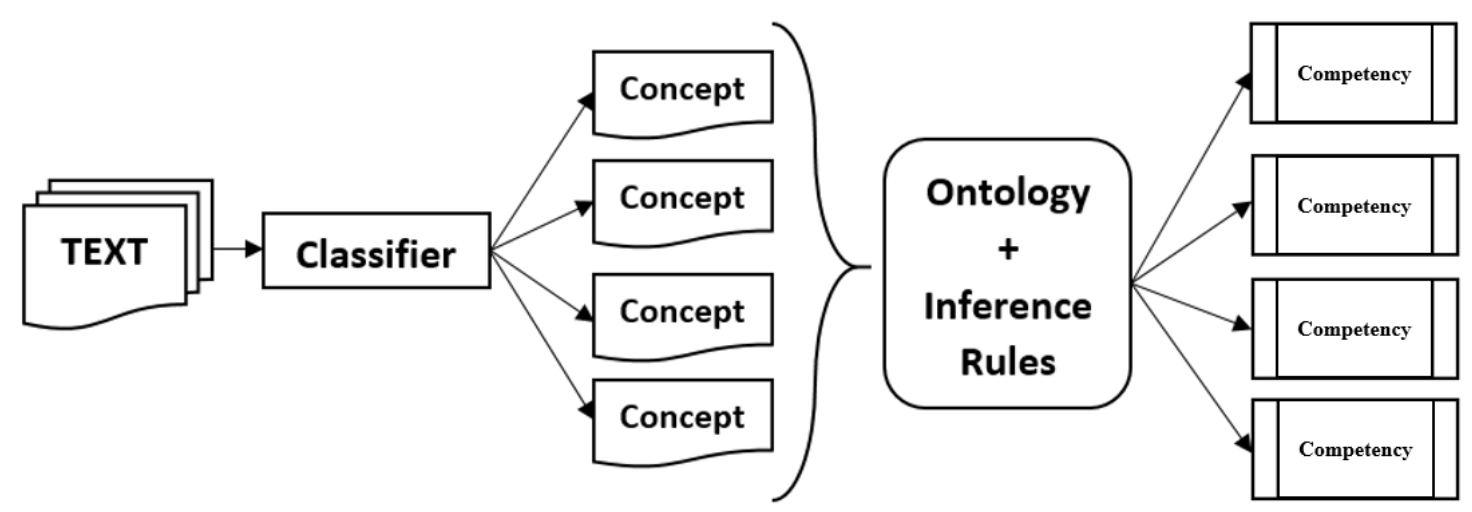

Figure 6. Results of the students' text analysis

\section{Latent competencies discovery}

The model provides the possibility to infer new competencies which are not explicitly represented in the student's model or knowledge-base and can be deduced by exploiting rule-based reasoning tactics. This process allows for enriching students' profile with new knowledge inferred by analysing their RDF file. The assessment module, which is based on the results of the analytics approaches presented in the previous section allows us to discover latent and implicit competencies that help to assess the student's level correctly. More complex inferences can be performed using a rule-based reasoning language, for instance, semantic web rule language (SWRL). In the following lines, an example of some of the inferring rules we developed are presented:

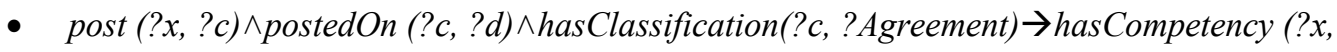
?Analysis)

This means: If $x$ posted a comment $c$ on object $d$, and after subjected the comment to discourse analysis module, the system discovers that $x$ shows a sense of acceptance about $d$. Then, it infers that $x$ has the analysis competency. The student cannot accept anything before they make mental reasoning and analysis.

- $\quad \operatorname{add}(? x, ? s) \wedge$ isSimilarTo (?s, ?t) $\rightarrow$ hasCompetency (?x, ?Adequation)

This means: If $x$ adds a summary $s$ and after subjecting it to the text comparison module, the system discovers that the summary of the student is likely similar to the teacher's summary. The system infers that the student has the competency of adequation. 
- $\quad$ ask (?y, ?definition)^about (?definition, 'Algorithm') $\wedge$ answer (?x, ?Example) $\wedge$ about (?Example, 'Algorithm') $\rightarrow$ hasCompetency (? $x$, ? Linking \& ? Mastery \& ? Reactivity \& ? Creativity)

This means: If a teacher $y$ asks for a definition about the algorithm domain, and the student $x$ answers with an example about algorithms, the system infers that student $x$ has the linking, mastery, reactivity, and creativity competencies. They are able to link a theoretical definition to a practical example, and this cannot be achieved unless their knowledge is well mastered, and they answered with another form than the requested answer of the teacher.

- $\quad$ ask $(? y, ? t) \wedge$ post (?x, ?image) $\wedge$ iTag (?image, ?u) $\wedge$ sameAs (?t, ?u) $\rightarrow$ hasCompetency (?x,

?Mastery \& ? Creativity \& ?Relevance)

This means: If a teacher $y$ asks for tagging a resource, and the student $x$ answers by posting an image, and then subjected the image to the image tagging module, the system extracts the tag of the image. After subjecting the latter to the ontology, the system discovers that the tag of the student is the same as the tag requested by the teacher. Then, the system infers that student $x$ has the mastery, relevance and creativity competencies.

- $\quad$ post $(? x, ? c) \wedge$ postedOn $(? c, ? d) \wedge$ hasClassification (?c, ?question) $\rightarrow$ has-Competency (?x,

?Argumentation)

This means: If student $x$ posted a comment $c$ on document $d$, and after subjected $c$ to discourse analysis module, the system discovers that student $x$ asks a lot of questions about $d$. Then, the system infers that student $x$ has the argumentation competency.

- $\quad \operatorname{post}(? x, ? p) \wedge$ postedOn(?p, ?lo $) \wedge($ isExpert $(? y, ? l o) \wedge$ hasCriticsOn $(? x, ? p)) \rightarrow$ hasCompetencyl (?y,?Analysis \& ?Reactivity)

This means: If student $x$ added a post on a learning object $l o$ and student $y$ who is an expert in the domain of $l o$ has criticised the post added by student $x$, the system infers that student $y$ has the analysis and reactivity competencies.

Figure 7 shows the new competencies discovered by the inferring rules using the N3 syntax. This new knowledge will be stored in the students' RDF files.

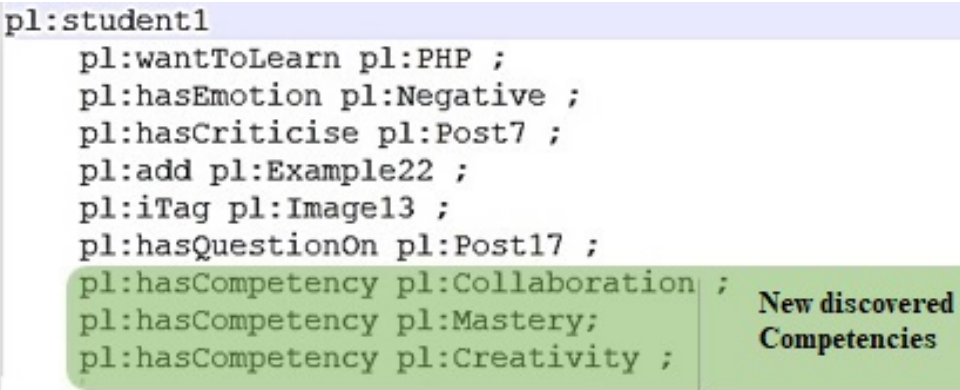

Figure 7. The student model after discovering new competencies

\section{How to decide if competency is acquired, to be acquired, or not acquired}

The decision on whether a competency has been acquired or not remains a very complicated process by humans, not to mention by a system. However, we provide this approach which is based on the use of the semantic and analytics modules presented previously to address the identified challenge. After enriching the students' model with the newly discovered knowledge (e.g., about their latent competencies), we can subject the student's RDF files to another analysis to decide whether the student has acquired the competency, is on the way to acquiring it, or has not acquired it yet. In the following paragraph, we present how the system makes such decisions.

In general, the analysis competency is discovered based on the critiques extracted from students' textual posts, using the discourse analysis module, for example, $<$ Student7, hasCriticsIn, post $11>$. The linking competency is discovered based on the semantic relations that relate concepts extracted from students' 
textual posts, namely: prerequisiteOf, isPartOf, same As. For instance, <Student2, wantToLearn, 'PHP'> and < Student7, add, 'HTML'> and <html, isPrerequisiteOf, 'PHP'>. The reactivity competency is discovered by extracting concepts through the use of the topics extraction. To do this, extracted concepts are compared with that of the teacher, and checked for similarity, $<$ Student 7 , add, Post $3>$ and $<$ Post 3 , hasConcept, Concept $8>$ and $<$ Concept3, sameAs, Concept $8>$ or $<$ Concept3, subClassOf, Concept $8>$. The creativity competency is discovered by extracting students' terminologies and to see if they use terminologies different from the teacher, but have semantic relations with terminologies suggested by the teacher. Creativity competency is also discovered by checking if the student uses different types of learning resources, $<$ Teacher1, add, Post $9>$ and $<$ Student7, add, Post5 $>$ and $<$ Post5, sameAs, Post9 $>$ and $<$ Post9, hasType, Text $>$ and $<$ Post5, hasType, Image $>$. The quality competency is discovered by checking the grammar of students, through the use of the grammar check module, <Student7, grammarLevel, 'advanced'>.

For example, the system could check in the student's model to ascertain if semantic predicates contain only critics statements. If so, the analysis competency is acquired. If the student's RDF file features a mix of critiques and agreements or appreciations, the student is on the way to acquiring the analysis competency. If the RDF file contains only a statement of acceptance without any sign of disagreement, the competency is not acquired. The same procedure was carried out for the other competencies by using the corresponding semantic statements and predicates. Figure 8, is an example of the syntax for the above-described process.

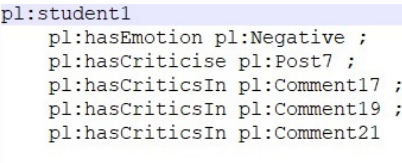

Acquired



To be Acquired

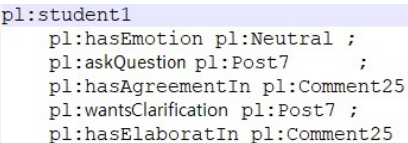

Not Acquired

Figure 8. Decisions regarding competencies acquisition

\section{Experiment set up}

The purpose of the experimentation in this study, which is divided into two parts, is to demonstrate the effectiveness of using the proposed semantic analytics approach to enhance students' evaluation. To this end, we used a random sampling technique where 12 students enrolled in the Department of Computer Science at Guelma University in the academic year 2019-2020, were randomly selected. With a margin of error $=3 \%$ and confidence level of $95 \%$, the sample was randomly selected from the 31 students registered on the SoLearn system. The selected students carried out the pedagogical scenario presented in Table 3 . The topic taken was general concepts on computing. Feedback on the system's usage was obtained through a survey. The same sample students were subjected to two different experiments.

\section{Experiment setting 1 (before/after situation)}

To verify if the semantic web and learning analytics method could enhance the students' evaluation process, the experiment was conducted in two stages. The first stage was done using the system with its reduced version, which includes only space for communication and resources exchange, to evaluate students using the classic method (true/false). The second stage was done using the system with all its features; social networking, semantic search, inferring, learning analytics, data visualisation, and recommendations, to evaluate the students by discovering their explicit and latent competencies.

Experiment setting 2

To validate the system's results, the assessment approach outcomes were checked against the teacher evaluation of students' competencies.

\section{Methodology}

In the experiment, we focused on the assessment of collaboration, creativity, quality, reactivity, analysing, and linking competencies. For this purpose, we asked the students to carefully examine and carry out the steps of the scenario presented in Table 3. 
Table 3

A scenario explaining how students' competencies are assessed

Competency 1: Processing and creativity

Master the notions of analysing and information selection



\section{Results}

First experimentation results

To learn the effectiveness of the approach, we tested the following hypothesis: 
Null hypothesis $\mathrm{H}_{0}$ : The use of semantic learning analytics has no effect on enhancing the students' evaluation process.

Alternate hypothesis $\mathrm{H}_{1}$ : The use of semantic learning analytics has an effect on enhancing the students' evaluation process.

As an example, to test the Null hypothesis $\mathrm{H}_{0}$, the creativity competency is discussed. The students were asked to tag the teacher's text with a set of tags representing their assimilation of the text content. The system in the first phase evaluated the students' answers by comparing, syntactically, their tags, to check if they exactly matched one of the teacher's tags. If so, the system indicated 2; if not 0 . In the second phase, the system subjected the students' tags to different learning analytics and semantic web modules in order to analyse the tags and check if the students used different terminologies from that of their teacher, while still having semantic relations with terminologies suggested by the teacher. The system indicated 3 if the student acquired the creativity competency, that is to say, their tags were exactly as the teacher's tags or they are other terminologies, but with the same meaning as the teacher's terminologies. When a student tagged the text with another form (a picture), the system referred the image tagging module, and extracted a tag that perfectly matched the teacher' tags. This resulted in a 1 (to be acquired) as the students' tags were not exactly alike, but related to the teacher's tags. The system indicated 0 when the tags were completely different (not acquired).

We compared the ranks of the two paired values where both observations were taken from the same participants (before and after using the semantic learning analytics approach). As the sample size was less than 30 and because we had two dependent samples for a non-parametric paired test, we used the Wilcoxon signed-rank test to assess whether the sample mean ranks differed. The test compared the probability of obtaining a higher value from group 1 with the probability of obtaining a higher value from dependent group 2. The results are presented in Table $4(\alpha=0.05)$.

Table 4

Results of the Wilcoxon signed-rank test

\begin{tabular}{lcrrrr}
\hline Situation & $N$ & $\begin{array}{c}\text { Sample average } \\
(X):\end{array}$ & Sample $S D(S):$ & $\begin{array}{c}\text { Standardised } \\
\text { effect size }\end{array}$ & $P$ value \\
\hline $\begin{array}{l}\text { Difference (After, } \\
\text { Before) }\end{array}$ & 12 & 0.8333 & 1.0298 & 0.762 & 0.03125 \\
\hline
\end{tabular}

The $Z$ score equalled -2.1538 , which was not in the 95\% region of acceptance (-1.9600: 1.9600). Wilcoxon signed-rank test value was 2.50 , and also not in the $95 \%$ region of acceptance $(4.3500: 31.6500)$. The observed standardised effect size, $Z / \sqrt{ } n$, was large (0.762) and indicated that the magnitude of the difference between the values of pre and post testing was large. The $p$-value equalled $0.03125,(p(x \leq Z)=0.01562)$. This indicated that the chance of Type 1 error (rejecting a correct $\left.\mathrm{H}_{0}\right)$ was small $(0.03125 ; 3.13 \%)$. The smaller the $p$-value the greater the support for $\mathrm{H}_{1}$. The difference between the value of the after minus before and expected difference $(\mu 0)$ was large enough to be statistically significant. Since the $p$ value was less than the $\alpha$ value, this provided evidence for the null hypothesis $\mathrm{H}_{0}$ to be rejected in favour of the alternative hypothesis $\mathrm{H}_{1}$. Therefore, the use of semantic learning analytics had a positive effect on enhancing the students' evaluation process.

To measure the reliability of the study, we used the test-retest reliability and assumed the construct was consistent across time. That is, a student who was assessed as having "acquired" a competency, should acquire it again in the next assessment after a week for example. At the least they would be assessed with a "to be acquired" decision. Assessing test-retest reliability requires using the measure on the sample at one time, using it again on the same sample at a later time, and then carrying out test-retest correlation between the two sets of scores. This is typically done by computing Pearson's $r$ correlation. Results of the Pearson correlation indicated that there was a significantly large positive relationship between the results of the first and second assessments $(r(10)=.76, p=.00443, r=0.7562)$. The result was considered to indicate good reliability.

\section{Second experiment results}

In the second experiment, we validated the results of the proposed approach by comparing it with the results of the teacher's evaluation. Both results are presented in Table 5. The system's decisions and teacher's 
evaluation varied from "acquired" to "to be acquired" and "not acquired" with corresponding values $(2,1$, $0)$.

Table 5

System's evaluation versus teacher's evaluation

\begin{tabular}{|c|c|c|c|c|c|c|c|c|c|c|c|c|}
\hline Competencies & \multicolumn{2}{|c|}{ Collaboration } & \multicolumn{2}{|c|}{ Creativity } & \multicolumn{2}{|c|}{ Quality } & \multicolumn{2}{|c|}{ Reactivity } & \multicolumn{2}{|c|}{ Analysing } & \multicolumn{2}{|c|}{ Linking } \\
\hline Student & $\mathrm{S}$ & $\mathrm{T}$ & $\mathrm{S}$ & $\mathrm{T}$ & $\mathrm{S}$ & $\mathrm{T}$ & $\mathrm{S}$ & $\mathrm{T}$ & $\mathrm{S}$ & $\mathrm{T}$ & $\mathrm{S}$ & $\mathrm{T}$ \\
\hline 1 & 2 & 1 & 1 & 2 & 1 & 1 & 0 & 0 & 2 & 2 & 2 & 2 \\
\hline 2 & 1 & 1 & 1 & 1 & 1 & 0 & 0 & 1 & 0 & 0 & 1 & 2 \\
\hline 3 & 0 & 0 & 2 & 0 & 1 & 1 & 1 & 2 & 1 & 1 & 2 & 1 \\
\hline 4 & 1 & 1 & 2 & 2 & 0 & 1 & 0 & 0 & 1 & 1 & 2 & 1 \\
\hline 5 & 2 & 2 & 1 & 2 & 0 & 0 & 2 & 0 & 0 & 2 & 1 & 0 \\
\hline 6 & 2 & 2 & 1 & 1 & 1 & 2 & 0 & 1 & 2 & 0 & 1 & 0 \\
\hline 7 & 0 & 1 & 2 & 0 & 1 & 0 & 1 & 2 & 1 & 2 & 1 & 2 \\
\hline 8 & 2 & 2 & 0 & 1 & 2 & 1 & 0 & 2 & 2 & 1 & 0 & 1 \\
\hline 9 & 1 & 0 & 2 & 2 & 2 & 2 & 2 & 1 & 0 & 1 & 1 & 0 \\
\hline 10 & 2 & 1 & 1 & 0 & 1 & 2 & 1 & 2 & 1 & 1 & 1 & 0 \\
\hline 11 & 2 & 2 & 0 & 0 & 0 & 0 & 0 & 1 & 2 & 1 & 2 & 0 \\
\hline 12 & 0 & 1 & 1 & 2 & 2 & 2 & 1 & 1 & 1 & 2 & 2 & 1 \\
\hline $\mathrm{CS}$ & \multicolumn{2}{|c|}{0.90} & \multicolumn{2}{|c|}{.071} & \multicolumn{2}{|c|}{0.84} & \multicolumn{2}{|c|}{0.57} & \multicolumn{2}{|c|}{0.70} & \multicolumn{2}{|c|}{0.69} \\
\hline
\end{tabular}

Note. $\mathrm{S}=$ system, $\mathrm{T}=$ teacher, $\mathrm{CS}=$ cosine similarity calculation

Figure 9 presents a set of diagrams representing the comparison results between the system's decisions and the teacher's evaluation for each competency: collaboration, creativity, quality, reactivity, analysing, and linking.
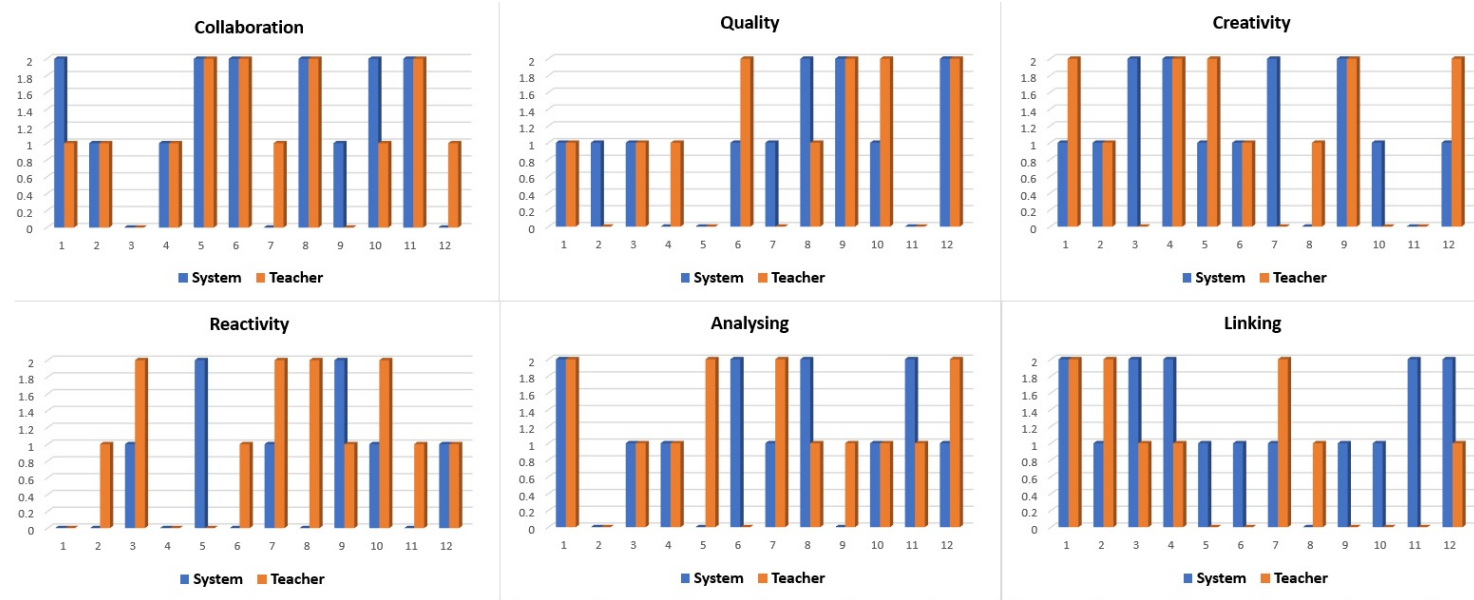

Figure 9. Results of the system decisions and the teacher's evaluation

Figure 10 presents a fragment of radar charts that were used to represent a series of the studied competencies of each student. Each series is identified by a different colour. The largest series to an axis represents the largest percentage of the competency. This figure presents the results for 4 students in the sample group and highlights competencies judged "acquired" by the system in comparison with those judged "acquired" by the teacher.
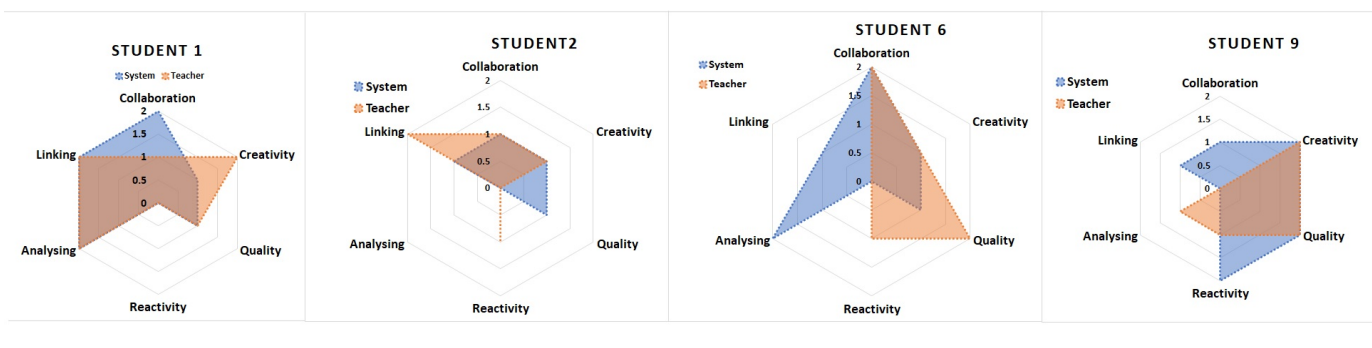
Figure 10. Comparison between acquired competencies by the system versus by the teacher for 4 students

\section{Discussion}

This study assessed the students' competencies, by combining the use of semantic web and learning analytics approaches. Data generated by the various learning activities was then analysed in order to discover and assess students' explicit and latent competencies. This provided a better understanding of how the process of competency assessment could be enhanced by using text mining techniques and ontological models. The assessment process takes advantage of the meaning expressed by semantics defined in the ontology. It also benefits from the discovery of new knowledge through the inferring mechanism of the semantic web and learning analytics.

This study established that using different learning analytic approaches pushed most students to use the main functionalities of the proposed system. They appreciated its main new feature, which was focused on the assessment by competencies. Students were impressed by the results of the different learning analytic components and how the results can be used to discover their hidden competencies. One student, for instance, said about the result of their discourse analysis: I was not aware that my critiques show me as competent in analysing discussion.

By analysing the charts presented in Figure 9, we can conclusively say that the results shown by the system are aligned with results given by the teacher. We also saw a high correlation between results for the competencies of collaboration, analysis, creativity, and quality. Less correlation was seen in the results of the competencies linking and reactivity. This was confirmed in Figure 10, where we saw that for Student 1, Student 2, and Student 9, the results of the competencies assessment were relatively close. This was evident at the intersection of the spaces representing the results of both the system and the teacher. For example, looking at the collaboration diagram, we can see that $58 \%$ of the students had the same evaluation by both the system and the teacher. If we consider that teacher's evaluation was closest to reality and if we consider that there was no difference between the "acquired" and "to be acquired" decisions provided by the system, we notice that $75 \%$ of the students had the same evaluation by both the system and the teacher.

The reactivity competency diagram presented in Figure 9 showed some differences in the results. We observed that $16 \%$ of the students had the same evaluation by both system and teacher. However, $42 \%$ of students had a different evaluation of the reactivity competency, with indications of "acquired" and "not acquired", and 33\% had mixed decisions between "acquired" and "to be acquired".

On one hand we found that the approach helped students discover their strengths and weaknesses, which guided them to achieve their educational goals accurately, in a flexible way and at their own pace. On the other hand, we found that the approach provided the teachers with clear instructions and good feedback on the teaching materials they provided to students. This allowed the teachers to make adjustments their courses or content. In addition, this may help the education authority to draw future directions for educational curricula, adapting them to students' abilities, strengthening their students' learning weaknesses and sustaining their strengths.

\section{Discussion of threats to validity}

To analyse and evaluate the threats to the validity of this study we used the generally accepted criteria for internal and external validity (Flannelly et al., 2018).

Internal validity

Internal validity is a quality indicator that allows the researcher to assess the reliability or certainty of their internal conclusions drawn from the statistical analysis of their own data. A number of potential threats to the internal validity of this study are listed and discussed below.

- Maturation: The passage of time allows candidates to potentially change; they tend to have more advanced knowledge in specific areas. As all students came from the same computer science background, most of them had the same cognitive understanding of the subject of the experiment. The experiment was also confined to a specified period of time, so there was no large potential for change over time. However, since students were only involved in the study for about 1 week, this 
was not considered a major threat. We do not believe that these issues were impacted on the outcomes of the study.

- Regression to the mean: When candidates take an assessment multiple times, their scores tend to regress, or fall back, to their own personal average. To ensure that the study had high reliability, the students did not undergo multiple assessments in different time stages but only in 1 week. We did not see that this affected the results of the study.

- Selection of subjects: Bias in the selection of candidates when building an assessment can have an impact on the results. A random selection of students was adopted for this experiment, to counter any selection effect on the results of the study.

- Mortality: Participants drop out of the process, resulting in differences between groups that may be unrelated to their assessment scores. All students who participated in the first stage of the experiment participated in the second stage and therefore this was not an issue that was important for the outcome of the study.

- Instrumentation: Changes in measurement can result in score differences that are due to the measurement procedures rather than true changes in individuals' performance ability. We handled this threat by keeping the assessment process consistent and ensuring that all students used the same functionality of the system.

- History: Specific events occurring between first and second measurements may cause a difference. We did not record any special events during the experiment, and therefore did not see that this threat effected the outcome of the study.

- Testing: With repeated testing, results can change due to practice effects or knowledge gains. We believe that we have handled this threat by providing all students with the same experiment material. All students took the same pre-test and post-test.

\section{External validity}

The external validity of a study describes the possibility to generalise its results. All participating students were enrolled in bachelor degree modules in computer science at Guelma University in 2019-2020. Because all Algerian universities adopt the same educational and pedagogical system, it was possible to generalise our results to all students in bachelor and masters programme in computer science or a related field in Algerian universities. However, we cannot say that it would be possible to generalise the findings to students in general, and we are not able to say that the result would be valid for other educational levels.

\section{Limitations}

Certain limitations are associated with empirical studies such as this study. Therefore, we accept that the lack in assessment of some competencies was perhaps due to access difficulties, even in the real classroom, by expert teachers. For this study, we believe that several parameters can influence the acquisition of the optimal results in future works. For instance, we would look at enhancing the definition of the competency according to the students' behaviour presented in Table 1, representing the maximum of concepts and relations in the ontology and the proposed inference rules, using other learning analytics tools to get more precise decisions, modelling the student's model with the Institute of Electrical and Electronics Engineers personal and private information standard (IEEE PAPI), and comparing the results with those obtained in this work, using a larger sample size to increases the statistical power of the subsequent analysis, to improve external validity. However, we firmly believe that developing the approach of semantic analytics assessment proposed in this study will undoubtedly help in the development of the assessment process.

\section{Conclusion}

Students of the digital age use learning systems based on the latest intelligent computing technologies, including those that integrate social media and intelligent agents. The resulting learning environments allow the learners to participate in knowledge creation and sharing anytime, anywhere, and anyway. One of the most important questions that we raised through this paper was how to successfully assess students' competencies when they use these sophisticated systems. To answer this question and according to the recommendations affirming that learning analytics approaches could support competencies' assessment (Chan et al., 2018), we proposed an approach that combined the use of learning analytics techniques and semantic modelling to verify, model, and analyse student activities to better assess their competencies. 
In this study, an emerging research field called, assessment analytics, has been presented. Assessment analytics focuses on the study of students' activities in order to extract and interpret new indicators, which contribute to the improvement of the evaluation process. We have highlighted the use of the semantic web to take advantage of its richness in knowledge representation. In particular, we have focused on semantic annotations of competencies and inferring of new knowledge in order to discover latent skills hidden behind student activities. We also highlighted how the process of competency assessment could be enhanced by using text mining techniques. This experimental study using the SoLearn system has indicated that this approach is efficient in modelling and evaluating students' competencies, and showed promising improvements in the design of competency-based assessment systems.

\section{References}

Abecker, A., \& Decker, S. (1999). Organizational memory: Knowledge acquisition, integration, and retrieval issues. In F. Puppe (Ed.), XPS-99, German conference on knowledge-based systems (pp. 113124). Springer. https://doi.org/10.1007/10703016 7

Adeshola, I., \& Abubakar, A. M. (2020). Assessment of higher order thinking skills: Digital assessment techniques. In E. Railean (Ed.), Assessment, testing, and measurement strategies in global higher education (pp. 153-168). IGI Global. https://doi.org/10.4018/978-1-7998-2314-8.ch008

Ahmed, I., Banu, H., Al-Fageer, R., \& Al-Suwaidi, R. (2009). Cognitive emotions: Depression and anxiety in medical students and staff. Journal of Critical Care, 24(3), e1-e7. https://doi.org/10.1016/j.jcrc.2009.06.003

Ally, M. (2019). Competency profile of the digital and online teacher in future education. International Review of Research in Open and Distributed Learning, 20(2), 302-318. https://doi.org/10.19173/irrodl.v20i2.4206

Ambarwati, A., \& Damayanti, V. (2021). Authentic assessment analysis of literary writing skills 'Poetry' based on the concept of creative thinking in students at Ihsaniyah High School. https://doi.org/10.2139/ssrn.3852114

Bayrak, F. (2021). Investigation of the web-based self-assessment system based on assessment analytics in terms of perceived self-intervention. Technology, Knowledge and Learning, 1-24. https://doi.org/10.1007/s10758-021-09511-8

Chan, T., Sebok-Syer, S., Thoma, B., Wise, A., Sherbino, J., \& Pusic, M. (2018). Learning analytics in medical education assessment: The past, the present, and the future. AEM Education and Training, 2(2), 178-187. https://doi.org/10.1002/aet2.10087

Choi, Y., \& Cho, Y. I. (2020). Learning analytics using social network analysis and Bayesian network analysis in sustainable computer-based formative assessment system. Sustainability, 12(19), 7950. https://doi.org/10.3390/su12197950

Cooper, A. (2015, June 9). Assessment analytics [Paper presentation]. EUNIS E-learning Task Force workshop, Dundee, Scotland. http://hdl.handle.net/11366/559

Coulet, J. C. (2011). La notion de compétence: Un modèle pour décrire, évaluer et développer les compétences. Le Travail Humain, 74, 1-30. https://doi.org/10.3917/th.741.0001

Ellis, C. (2013). Broadening the scope and increasing the usefulness of learning analytics: The case for assessment analytics. British Journal of Educational Technology, 44(4), 662-664. https://doi.org/10.1111/bjet.12028

Feldman, R. S., \& Prohaska, T. (1979). The student as Pygmalion: Effect of student expectation on the teacher. Journal of Educational Psychology, 71(4), 485. https://doi.org/10.1037/0022-0663.71.4.485

Flannelly, K. J., Flannelly, L. T., \& Jankowski, K. R. (2018). Threats to the internal validity of experimental and quasi-experimental research in healthcare. Journal of Health Care Chaplaincy, 24(3), 107-130. https://doi.org/10.1080/08854726.2017.1421019

Halimi, K., \& Seridi-Bouchelaghem, H. (2019). A Web3. 0-based intelligent learning system supporting education in the 21st century. Journal of Universal Computer Science, 25(10), 1373-1393. https://doi.org/10.3217/jucs-025-10-1373

Halimi, K., Seridi-Bouchelaghem, H., \& Faron-Zucker, C. (2014). An enhanced personal learning environment using social semantic web technologies. Interactive Learning Environments, 22(2), 165 187. https://doi.org/10.1080/10494820.2013.788032

Haugen, K., \& Metcalf, K. L. (2019). Assessment of online learning. Radiologic Technology, 90(3), $307-$ 311 PMID: 30635464

Idrissi, M. K., Hnida, M., \& Bennani, S. (2020). Competency-based assessment: From conceptual model to operational tool. In I. Management Association (Ed.), Learning and performance assessment: 
Concepts, methodologies, tools, and applications (pp. 108-129). IGI Global. https://doi.org/10.4018/978-1-7998-0420-8.ch006

Johnson, R. L., Penny, J. A., \& Gordon, B. (2008). Assessing performance: Designing, scoring, and validating performance tasks. Guilford Press. https://psycnet.apa.org/record/2008-15949-000

Kamalova, M., Anvarshed, T., Makhmatkulova, G., Rakhmonova, M., Makhmudova, S., \& Turaev A. (2021). Observed frequent stress among students before exams. International Journal of Academic Multidisciplinary Research, 5(3), 24-26. http://www.ijeais.org/ijamr/index.php/ijamr-5-3-2021/

Khdour, T. (2020). A semantic assessment framework for e-learning systems. International Journal of Knowledge and Learning, 13(2), 110-122. https://doi.org/10.1504/IJKL.2020.106648

Koretz, D. M. (2002). Limitations in the use of achievement tests as measures of educators' productivity. Journal of Human Resources, 37(4), 752-777. https://doi.org/10.2307/3069616

Larrabee Sønderlund, A., Hughes, E., \& Smith, J. (2019). The efficacy of learning analytics interventions in higher education: A systematic review. British Journal of Educational Technology, 50(5), 2594 2618. https://doi.org/10.1111/bjet.12720

Lasnier, F. (2000). Réussir la formation par compétences. Guérin éditeur ltée.

Mayfield, J., \& Finin, T. (2003). Information retrieval on the semantic web: Integrating inference and retrieval. Proceedings of the International ACM SIGIR Conference on Research and Development in Information Retrieval Workshop on the Semantic Web, Toronto.

https://ebiquity.umbc.edu/paper/html/id/88/Information-retrieval-on-the-Semantic-Web-Integratinginference-and-retrieval

Namahoot, C. S., Brückner, M., \& Nuntawong, C. (2020). CLASS-O, a cooperative language assessment system with ontology. In Y. Luo (Ed.). Cooperative design, visualization, and engineering: Lecture notes in computer science (pp. 167-177). Springer. https://link.springer.com/chapter/10.1007/978-3030-60816-3 19

Nkhoma, C., Dang-Pham, D., Hoang, A. P., Nkhoma, M., Le-Hoai, T., \& Thomas, S. (2020). Learning analytics techniques and visualisation with textual data for determining causes of academic failure. Behaviour and Information Technology, 39(7), 808-823. https://doi.org/10.1080/0144929X.2019.1617349

Okoye, K., Islam, S., Naeem, U., Sharif, M. S., \& Sharif, S. (2020). Semantic-based process mining technique for annotation and modelling of domain processes. International Journal of Innovative Computing, Information and Control, 16(3), 899-921. https://doi.org/10.24507/ijicic.16.03.899

Paquette, G. (2002). L'ingénierie pédagogique (1st ed.). Presses de l'Université du Québec. https://doi.org/10.2307/j.ctv18ph0c9.11

Patterson, F., Tavabie, A., Denney, M., Kerrin, M., Ashworth, V., Koczwara, A., \& MacLeod, S. (2013). A new competency model for general practice: implications for selection, training, and careers. The British Journal of General Practice, 63(610), e331-e338. https://doi.org/10.3399/bjgp13X667196

Rafiola, R., Setyosari, P., Radjah, C., \& Ramli, M. (2020). The effect of learning motivation, selfefficacy, and blended learning on students' achievement in The Industrial Revolution 4.0. International Journal of Emerging Technologies in Learning, 15(8), 71-82. https://doi.org/10.3991/ijet.v15i08.12525

Rayón, A., Guenaga, M., \& Núñez, A. (2014). Supporting competency-assessment through a learning analytics approach using enriched rubrics. Proceedings of the Second International Conference on Technological Ecosystems for Enhancing Multiculturality, Salamanca, Spain, 291-298. https://doi.org/10.1145/2669711.2669913

Rezgui, K., \& Mhiri, H. (2020). Towards a semantic framework for lifelong integrated competency management and development. The Computer Journal, 63(7), 1004-1016. https://doi.org/10.1093/comjnl/bxz067

Romero, C., \& Ventura, S. (2020). Educational data mining and learning analytics: An updated survey. WIREs Data Mining and Knowledge Discovery, 10(3). https://doi.org/10.1002/widm.1355

Romero, L., Gutiérrez, M. D. L. M., \& Caliusco, M. L. (2012). Conceptualizing the e-learning assessment domain using an ontology network. International Journal of Artificial Intelligence and Interactive Multimedia, 1(6) 20-28. https://doi.org/10.9781/ijimai.2012.163

Siemens, G. (2013). Learning analytics: The emergence of a discipline. American Behavioral Scientist, 57(10), 1380-1400. https://doi.org/10.1177/0002764213498851

Zlatkin-Troitschanskaia, O., \& Pant, H. A. (2016). Measurement advances and challenges in competency assessment in higher education. Journal of Educational Measurement, 53(3), 253-264. https://doi.org/10.1111/jedm.12118 
Corresponding author: Khaled HALIMI, halimi.khaled@univ-guelma.dz

Copyright: Articles published in the Australasian Journal of Educational Technology (AJET) are available under Creative Commons Attribution Non-Commercial No Derivatives Licence (CC BY-NCND 4.0). Authors retain copyright in their work and grant AJET right of first publication under CC BYNC-ND 4.0.

Please cite as: Halimi, K., \& Seridi-Bouchelaghem, H. (2021). Students' competencies discovery and assessment using learning analytics and semantic web. Australasian Journal of Educational Technology, 37(5), 77-97. https://doi.org/10.14742/ajet.7116 